\title{
POTENTIAL OF FUNCTIONALISED CELLULOSE FROM OIL PALM BIOMASS AS NITROGEN AND PHOSPHORUS BASED NUTRIENT ADSORBENT - A REVIEW
}

\author{
MEI MEI CHONG*; LIAN SEE TAN*; NURFATEHAH WAHYUNY CHE JUSOH*; MASAFUMI GOTO* \\ and SUMATHI SETHUPATHI**
}

\begin{abstract}
By the year 2020, oil palm biomass in Malaysia is projected to reach between 85-110 million tonnes per year. Instead of disposing off such a massive amount of biomass as waste, the oil palm biomass could be converted into value-added products. Since lignocellulosic materials could be a suitable adsorbent for nitrogen and phosphorus-based nutrients from aquaculture effluent based on studies conducted by other countries, it would be an excellent opportunity to monetise oil palm biomass for a similar purpose as well. There are many well-established extraction methods introduced by researchers. However, only a handful of the extraction method involved the use of green chemicals. This paper provides a review of the extraction and modification for oil palm biomass towards becoming a potential adsorbent for nitrogen and phosphorus-based nutrients.
\end{abstract}

Keywords: Oil palm biomass, cellulose, adsorption, nitrate, phosphate.

Received: 11 November 2019; Accepted: 4 July 2020; Published online: 14 October 2020.

\section{INTRODUCTION}

Malaysia is the second-largest palm oil producer globally, following behind Indonesia (Abdullah and Sulaiman, 2013; Kushairi et al., 2019). Oil palm was introduced to Malaya in the year 1871 and the first commercial oil palm plantation started in the year 1917 at Tennamarran Estate in Selangor, Malaya (Awalludin et al., 2015; Onoja et al., 2019). Since then, oil palm has been planted extensively in Malaysia until present as Malaysia's tropical weather suits the required condition to plant the oil palm trees (Kamil

* Department of Chemical and Environmental Engineering, Malaysia - Japan International Institute of Technology, Universiti Teknologi Malaysia, Jalan Sultan Yahya Petra, 54100 Kuala Lumpur, Malaysia

** Department of Environmental Engineering, Faculty of Engineering and Green Technology, Universiti Tunku Abdul Rahman, Jalan University, Bandar Barat, 31900 Kampar, Perak, Malaysia.

E-mail: tan.liansee@utm.my and Omar, 2016). Subsequently, the amount of biomass from oil palm also inadvertently increases with the extensive planting of oil palm. By the year 2020, oil palm biomass in Malaysia is projected to reach between 85 to 110 million tonnes per annum (Malaysian-German Chamber of Commerce and Industry, 2017). Generally, oil palm generates six types of biomass, namely oil palm fronds (OPF), oil palm trunk (OPT), oil palm empty fruit bunch (OPEFB), fresh-pressed fibre, oil palm shell, and palm oil mill effluent (POME) (Abdullah and Gerhauser, 2008; Shuit et al., 2009; Umar et al., 2013; Zakaria et al., 2014; Lamaming et al., 2017; Mohd Rasli et al., 2017; Mohtar et al., 2017). According to Onoja et al. (2018), 75\% of the oil palm biomass is from OPF and OPT while the other biomass covers the remaining 25\%. Comparing OPF and OPT, OPF has higher cellulose content with $60 \%$ of the cellulose is in the basal portion, and $40 \%$ in the leaf (Malaysia Innovation Agency, 2013). However, currently, usage of OPF is limited to a few industries such 
as for steam production, bio-sugar production and fertiliser (Malaysia Innovation Agency, 2013). Rather than treating it as a common agricultural waste, the high cellulose content can be extracted and isolated for modification into a useful adsorbent.

On the other hand, other than oil palm production, Malaysia covers $1 \%$ of the world's seafood supply (Mohamed Omar, 2017b). Here is where the aquaculture industry plays a role where numerous aquaculture industrial zones were reserved for farmed fishes for the purpose of satisfying the global seafood demand (FAO, 2016). Aquaculture in Malaysia is categorised into marine and freshwater, whereby freshwater fishes are highly in demand and provide the most job opportunities compared to marine aquaculture (Mohamed Omar, 2017a). However, the downside of freshwater aquaculture is that the water used to farm fishes has to be replaced once every several months due to excessive nutrients content. Nutrients such as nitrate and phosphate are the main source of eutrophication condition (Cripps and Bergheim, 2000; Wang et al., 2010; Castine et al., 2013; Hokkanen et al., 2016; Kim et al., 2016; Yin et al., 2018; Pan et al., 2018; Wu et al., 2019; Karthikeyan et al., 2019; Lee et al., 2019). It can disrupt the fishes' respiratory system and decrease the dissolved oxygen in the water (Kioussis et al., 2000; Anirudhan et al., 2006; Ng et al., 2018). Other than aquaculture effluent, the sources of nitrate and phosphate nutrients in running water are livestock manure (Yin et al., 2017) and excessive use of fertiliser in industries (Keränen et al., 2013). These would eventually cause the nitrate and phosphate nutrients to leach into receiving water bodies and contaminating it. Overdose of phosphate nutrients can also cause disorder in the growth of seaweed and aquatic plants (Kioussis et al., 2000; Anirudhan et al., 2012; Turcios and Papenbrock, 2014). Over the concentration threshold of nitrate anion nutrients can result in methemoglobinaemia 'baby blue' syndrome in infants, formation of carcinogenic nitrosamines, and nitrosamides upon human consumption (Hamoudi and Belkacemi, 2013). Hence, proper effluent treatment is required to reduce the concentration of both nitrate and phosphate nutrients in the aquaculture effluent before it can be released to receiving water bodies or reused back into aquaculture.

Various treatments based on biological (Lin et al., 2002; Akinbile and Yusoff, 2012) and physicochemical (Kioussis et al., 2000; Orlando et al., 2002; Wang et al., 2007; Anirudhan and Senan, 2011; Keränen et al., 2013; Sehaqui et al., 2016; Fan and Zhang, 2018; Qiao et al., 2019; Stjepanović et al., 2019; Shojaipour et al., 2020) methods have been studied for the adsorption of nutrients from wastewater. However, the adsorption method using biomass must be brought to attention as agriculture waste is relatively cheap, and it serves great flexibility in the aquaculture industry.
Typically, activated carbon was used as an adsorbent but due to the increasing cost, many ventured into cheaper alternative solutions to adsorb the nutrients (Stjepanović et al., 2019; Yu et al., 2019).

Therefore, this paper aims to review the current trend of adsorption of the nitrate and phosphate nutrients and delve into the potential of functionalised cellulose from oil palm biomass as nitrate and phosphate nutrients adsorbent.

\section{ADSORPTION OF NITRATE AND PHOSPHATE}

The adsorption of nitrate and phosphate nutrients from aquaculture effluent has been studied using different lignocellulosic materials and water treatments. Table 1 shows a summary of the study on the adsorption of nitrate and phosphate anion nutrients previously conducted by other researchers. Based on the studies, the adsorption of the nutrients can generally be conducted at ambient conditions. Biological methods would require a longer duration (between weeks to months) to obtain significant results. Meanwhile, adsorption of the nutrients via adsorption method can be accomplished within hours. These studies accentuate the efficiency of the adsorption method for adsorption of the nitrogen and phosphorus-based nutrients.

The modification of polymer hydrogel was created to have positive charge ends to attract the negatively charged nitrate and phosphate by Kioussis et al. (2000). A hydrogel is a threedimensional polymer with hydrophilic property. Polymer hydrogel can be made of different polymer composition depending on the desirable properties. Based on Kioussis et al. (2000), poly(allylamine) hydrochloride was used to make the polymer hydrogel. It is a water-soluble cationic polymer and can be highly water-swollen hydrogel with chemical crosslinking. The poly(allylamine) hydrochloride polymer hydrogel has pendant primary amino groups where it will selectively attract anion nutrients via electrostatic force and trap the nutrients in the gel network. The equilibrium adsorption of nitrate and phosphate anion nutrients was obtained in $3 \mathrm{hr}$ with a neutral $\mathrm{pH}$ of the wastewater. In addition, the hydrogels could potentially be reusable for up to five cycles to achieve maximum adsorption. Shojaipour et al. (2020) conducted a study on the efficiency of nitrate adsorption on modified hydrogel with quaternary ammonium salt. The gum tragacanth biopolymer hydrogel was functionalised with $\mathrm{N}$-(trimethylsilyl) imidazole and (3-chloropropyl) trimethoxysilane to adsorb nitrate anion nutrient via ion exchange. The highest adsorption of nitrate anion nutrient obtained was at a neutral $\mathrm{pH}(\mathrm{pH} \mathrm{7.0)}$ in $20 \mathrm{~min}$. This would allow the hydrogels to be conveniently used without using $\mathrm{pH}$ adjuster in wastewater. 
TABLE 1. COMPILATION OF MULTIPLE TREATMENT TYPE FOR NITRATE AND PHOSPHATE ANION NUTRIENTS

\begin{tabular}{|c|c|c|c|c|c|}
\hline \multirow[b]{2}{*}{ Type of treatment } & \multicolumn{3}{|c|}{ Parameter } & \multirow{2}{*}{$\begin{array}{l}\text { Recovery/removal } \\
\text { performance }\end{array}$} & \multirow[b]{2}{*}{ Reference } \\
\hline & $\begin{array}{l}\text { Temperature } \\
\left({ }^{\circ} \mathrm{C}\right)\end{array}$ & $\mathrm{pH}$ & Time & & \\
\hline $\begin{array}{l}\text { Amine cross-linked tea } \\
\text { waste via adsorption }\end{array}$ & 25.0 & $3.0-10.0$ & $60 \mathrm{~min}$ & $\begin{array}{l}\text { Nitrate: } 136.43 \mathrm{mg} \mathrm{g}^{-1} \\
\text { Phosphate: } 98.73 \mathrm{mg} \mathrm{g}^{-1}\end{array}$ & Qiao et al (2019) \\
\hline $\begin{array}{l}\text { Brewer's spent grain via } \\
\text { adsorption }\end{array}$ & 25.0 & $4.0-10.0$ & $60 \mathrm{~min}$ & Nitrate: $22.65 \mathrm{mg} \mathrm{g}^{-1}$ & Stjepanović et al. (2019) \\
\hline $\begin{array}{l}\text { Constructed wetlands } \\
\text { system }\end{array}$ & $24.3-29.6$ & - & 1-7 months & $\begin{array}{l}\text { Nitrate: } 86.0 \%-98.0 \% \\
\text { Phosphate: } 32.0 \%-71.0 \%\end{array}$ & Lin et al. (2002) \\
\hline $\begin{array}{l}\text { Corn stalks cellulose via } \\
\text { adsorption }\end{array}$ & 25.0 & 6.80 & $6 \mathrm{hr}$ & $\begin{array}{l}\text { Nitrate: } 13.6054 \mathrm{mg} \mathrm{g}^{-1} \\
\text { Phosphate: } 22.8833 \mathrm{mg} \mathrm{g}^{-1}\end{array}$ & Fan and Zhang (2 \\
\hline $\begin{array}{l}\text { Gum tragacanth } \\
\text { carbohydrate produce } \\
\text { hydrogel via adsorption }\end{array}$ & 25.0 & Neutral & $20 \mathrm{~min}$ & Nitrate: $98.26 \%$ & Shojaipour et al. 2020) \\
\hline $\begin{array}{l}\text { Nanofibers from waste } \\
\text { pulp residues via } \\
\text { adsorption }\end{array}$ & 25.0 & $5.0-7.0$ & $24 \mathrm{hr}$ & $\begin{array}{l}\text { Nitrate: } 39.0 \% \\
\text { Phosphate: } 61.0 \%\end{array}$ & Sehaqui et al. (2016) \\
\hline $\begin{array}{l}\text { Novel cellulose-based via } \\
\text { adsorption }\end{array}$ & 30.0 & 6.0 & $6 \mathrm{hr}$ & Phosphate: 9 & Anirudhan and Senan \\
\hline $\begin{array}{l}\text { Pine sawdust, pine bark, } \\
\text { spruce bark, birch bark, } \\
\text { birch pear via adsorption }\end{array}$ & 25.0 & $3.0-10.0$ & $5-10 \mathrm{~min}$ & Nitrate: $70.0 \%-86.0 \%$ & Keränen et al. (2013) \\
\hline $\begin{array}{l}\text { Polymer hydrogels via } \\
\text { adsorption }\end{array}$ & 25.0 & 7.7 & $3 \mathrm{hr}$ & $\begin{array}{l}\text { Nitrate: } 50.0 \% \\
\text { Phosphate: } 98.0 \%\end{array}$ & Kioussis et al. (2000) \\
\hline $\begin{array}{l}\text { Sugarcane bagasse via } \\
\text { adsorption }\end{array}$ & 30.0 & 6.5 & $24 \mathrm{hr}$ & $\begin{array}{l}\text { Nitrate: } 9.0 \mathrm{mg} \text { litre }{ }^{-1} \\
\text { Phosphate: } 4.0 \mathrm{mg} \text { litre }^{-1}\end{array}$ & Orlando et al. (2002) \\
\hline $\begin{array}{l}\text { Water hyacinth and lettuce } \\
\text { via biological method }\end{array}$ & $25.0-35.0$ & 6.72 & 1-4 weeks & $\begin{array}{l}\text { Nitrate: } 90.92 \%, 39.78 \% \\
\text { Phosphate: } 83.59 \%, 55.90 \%\end{array}$ & Akinbile and Yusoff (2012) \\
\hline Wheat straw via adsorption & 24.0 & 6.8 & $150 \mathrm{~min}$ & Nitrate: $80 \%$ & Wang et al. (2007) \\
\hline
\end{tabular}

Besides hydrogel, lignocellulosic materials such as corn stalks, waste pulp residues, sugarcane bagasse, and wheat straws were studied as an adsorbent for nitrate and phosphate nutrients as well. These lignocellulosic materials were pretreated to extract and isolate cellulose compound, and it was further modified via cationisation to form a positively charged ends (Orlando et al., 2002; Wang et al., 2007; Keränen et al., 2013; Sehaqui et al., 2016; Fan and Zhang, 2018; Qiao et al., 2019; Stjepanović et al., 2019). These positively charged ends will attract the negatively charged nitrate and phosphate ions present in the aquaculture effluent via electrostatic attraction (Keränen et al., 2013; Qiao et al., 2019; Stjepanović et al., 2019). Electrostatic attraction force creates a strong bond between the positively and negatively charged particles and provides easy desorption by adding used adsorbent into sodium chloride ( $\mathrm{NaCl}$ ) solution (Keränen et al., 2013).

Cationisation of cellulose performed to functionalise for the adsorption of nitrate and phosphate nutrients is commonly achieved via quaternary ammonium salts. This allows ammonium positive ends to be grafted onto the cellulose, which promotes the adsorption of nitrate and phosphate anion nutrients. The adsorption will then be carried out via electrostatic force and ion exchange (with the presence of chlorine anions from the chemical used for quaternary ammonium salts) (Shojaipour et al., 2020).

During the adsorption of nitrate and phosphate anion nutrients, the surrounding parameters play a significant role. The varying parameters such as $\mathrm{pH}$ of adsorbate solution, the temperature of adsorbate solution, and contact time between the adsorbent and adsorbate should be monitored to obtain high adsorption capacities of nitrate and phosphate anion nutrients. Studies have shown that $\mathrm{pH}$ of aquaculture effluent within the range of 3.0-10.0 would be an optimal range for the adsorption of nitrate and phosphate (Kioussis et al., 2000; Orlando et al., 2002; Wang et al., 2007; Keränen et al., 2013; Sehaqui et al., 2016; Fan and Zhang, 2018; Yin et al., 2018; Karthikeyan et al., 2019; Qiao et al., 2019; Stjepanović et al., 2019; Wu et al., 2019). However, the highest adsorption capacities of the nitrate and phosphate anion nutrients were usually achieved within a pH of 5.0-6.5 (Keränen et al., 2013; Qiao et al., 2019; Stjepanović et al., 2019). This could be because of the dominant presence of $\mathrm{CI}^{-}$ions on the surface 
of active sites of the adsorbent when the $\mathrm{pH}$ is lower than 3.0, thus, reducing the electrostatic force between nitrate and phosphate anions and the active sites of the adsorbent (Stjepanović et al., 2019). When the $\mathrm{pH}$ is higher than 10.0, the competition between $\mathrm{OH}^{-}$ions and both nitrate and phosphate anions will occur, leading to electrostatic repulsion and lower available active sites on the surface of the adsorbent (Qiao et al., 2019).

The temperature of the solution plays a vital role in the adsorption of nitrate and phosphate anion nutrients as well. As reported by Shojaipour et al. (2020), increasing the temperature from $25^{\circ} \mathrm{C}-45^{\circ} \mathrm{C}$, the adsorption capacity of nitrate anion nutrients had decreased. The decrease in adsorption capacity is due to the exothermic reaction exerted during the adsorption process (Shojaipour et al., 2020). Thus, with higher temperatures, the electrostatic bond between the nitrate anion and cationic end of adsorbent might be weakened.

The effect of contact time between the adsorbent and the nitrate and phosphate anion nutrients serve as a function to provide sufficient time for nitrate and phosphate anion nutrients to fill up all vacant pores on the surface of the adsorbent. Hence, reaching an equilibrium concentration before the used adsorbent undergoes desorption for reusability purposes. As shown in Table 1, constructed wetlands systems (Lin et al., 2002) and biological method of adsorption via water hyacinth and lettuce (Akinbile and Yusoff, 2012) required a longer time to achieve better adsorption capacity of nitrate and phosphate anion nutrients. Although the biological method is an alternatively cheap method, it reacts relatively slow when the effluent contains a high load of nitrate and phosphate anion and low temperature (Stjepanović et al., 2019). The same concept applies to constructed wetland systems where it is dependent on the microbial's reactivity to treat the nitrate and phosphate anion loaded effluent (Lin et al., 2002).

\section{OIL PALM BIOMASS}

Since lignocellulosic material is currently in focus to act as an adsorbent, oil palm biomass could be a good representation of lignocellulosic material. In Figure 1, the detailed composition of oil palm biomass consists of cellulose, hemicellulose, and lignin. Each type of biomass has its unique characteristic which differs from one another.

Lignin is the aromatic polymer in the lignocellulose components. It has a random substitution arrangement of phenylpropane monomeric units which consist of syringly and guaiacyl $p$-hydroxylphenyl units (Klemm et al., 2005). On the other hand, hemicellulose has different monosaccharide units which are pentose sugar dominant. It can exist in the forms of either homopolymer or hetero-polymer, and it is alkali-soluble (Malaysia Innovation Agency, 2013; Kumneadklang et al., 2019) Hence, it is the main component in the production of bio-sugar due to its high sugar composition and easy hydrolysis process (Malaysia Innovation Agency, 2013). Meanwhile, cellulose is a linear homopolymer formed from the repeating D-anhydroglucosepyranose (AGU) monomers which are connected by $\beta$-(1,4)-glycosidic linkages (Klemm et al., 2005). Each monomer is rotated $180^{\circ}$ with respect to one another in the arrangement of the polymer, giving it the crystalline structure. Hence, this structure makes cellulose resistant to acid and enzymatic hydrolysis.

Since oil palm biomass is a major representation of lignocellulosic material in Malaysia with an abundance amount, the cellulose content can be extracted and functionalised to adsorb nitrate and phosphate nutrient ions. This study aids in reducing the amount of oil palm biomass by expanding its product value as well as providing an alternative method in wastewater treatment.

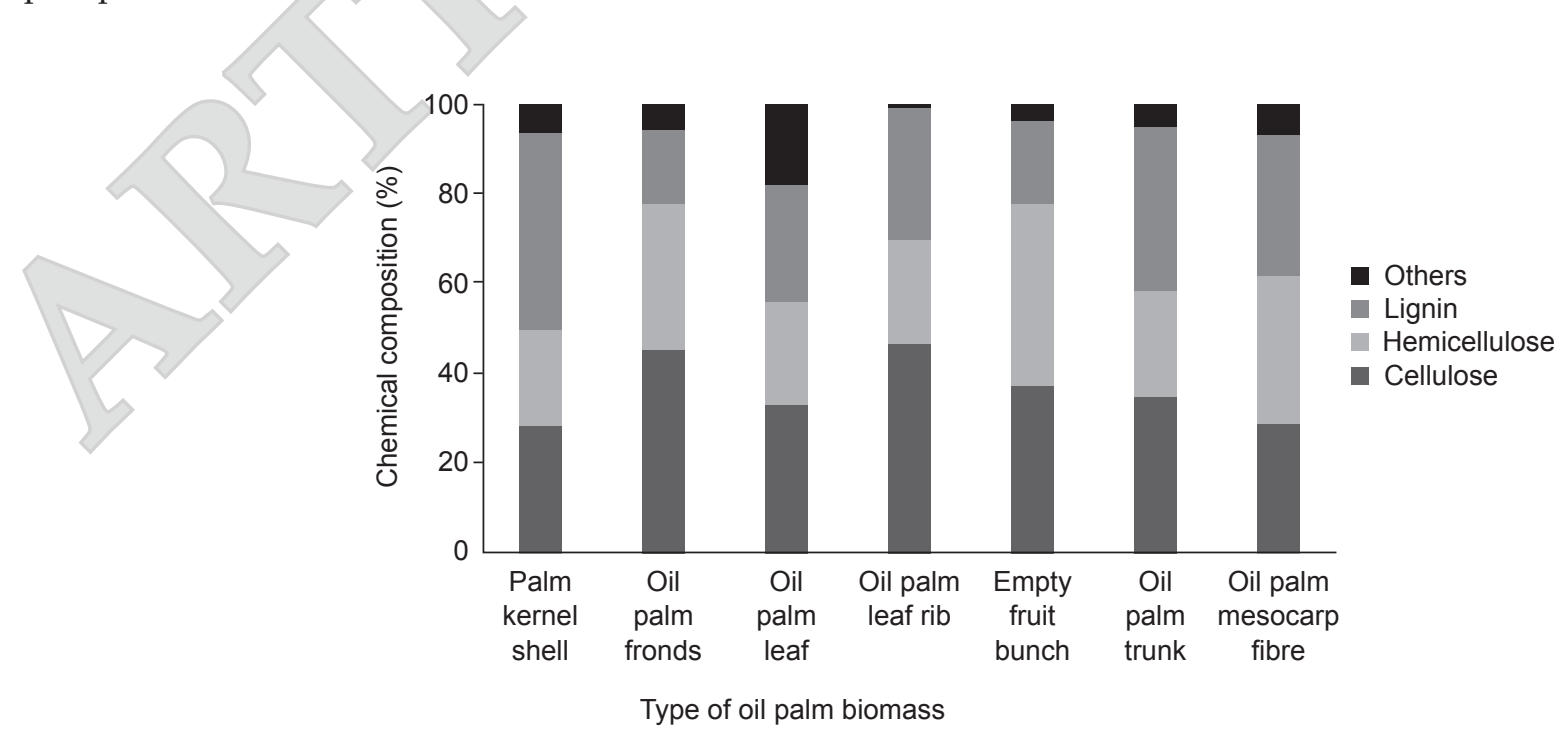

Figure 1. Chemical composition of different types of oil palm biomass (\% dry weight). 


\section{GENERAL USE OF OIL PALM BIOMASS IN ADSORPTION}

For the past years, oil palm biomass was studied to expand its product value (Abdullah and Gerhauser, 2008; Sumathi et al., 2008; Abnisa et al., 2011; Tan and Lee, 2012; Nazir et al., 2013; Zakaria et al., 2014; Awalludin et al., 2015; Lefatshe et al., 2017; Ooi et al., 2017). The expansion of oil palm biomass as an adsorbent was one of the studies which are still ongoing in the current research field. Researchers had been utilising the lignocellulosic material into adsorbing pollutants, especially dyes and heavy metals, in various forms of the adsorbent. Table 2 shows a summary of the usage of different types of oil palm biomass in adsorption of dye and heavy metal studies through the years.

Oil palm biomass had been mainly used in the study of adsorption on dyes and heavy metals. The oil palm biomass was either used in its isolated cellulose form (Hasnain et al., 2007; Saman et al., 2018), or it was further processed into microcrystalline cellulose (Hussin et al., 2016), activated carbon (Ooi et al., 2017), or biochar (Daneshfozoun et al., 2017). This showed the flexibility of using lignocellulose material, such as oil palm biomass itself, to be an excellent adsorbent for charged ions with or without pre-treatment.

The introduction of oil palm biomass into adsorption started with using oil palm ash. Oil palm ash is the leftover after oil palm biomass was used in burners to produce steam. Essentially, Hasnain et al. (2007) discovered that this oil palm ash contains carbonaceous compounds with the presence of pores on them. Therefore, the ash was used to adsorb dyes such as disperse blue and disperse red which are commonly found in textile related industrial wastewater due to colouring of products (Hasnain et al., 2007). Methylene blue was another common adsorbate for study on the adsorption towards oil palm biomass (Hussin et al., 2016; Shanmugarajah et al., 2019). The adsorption of dyes towards oil palm biomass was proven to be feasible under certain parameters. However, the modification of $\mathrm{pH}$ was often needed for high adsorption efficiency.

Another form of adsorbate used to study the adsorption capability of oil palm biomass was heavy metals. Iron (III), lead (VI), lead (II), hexavalent Chromium (VI), copper (II), zinc(II), nickel (II), and manganese (II) are examples of heavy metals used by previous researchers in their field of study on adsorption of heavy metals on oil palm biomass (Hasnain et al., 2008; Khosravihaftkhany et al., 2013; Daneshfozoun et al., 2017; Saman et al., 2018). The studies indicated good adsorption performance under alkaline $\mathrm{pH}$ and with quick equilibrium adsorption contact time. Hence, it is safe to say that the study of adsorption on oil palm biomass with dyes and heavy metals are well established. In addition, as shown in Table 2, the tested methylene blue dye favoured adsorption in acidic solution while heavy metals favoured adsorption in alkaline solution. This condition would require an additive to adjust the $\mathrm{pH}$ of wastewater prior to the adsorption process, and it could incur additional cost and a more complex operational handling. The concentration of the dye and heavy metals in the wastewater plays a vital role as well, due to the limitation of adsorption capacity of the adsorbent. Thus, usually, the higher the concentration, the lower the percentage removal of the dye and heavy metals. The highest removal percentage $(\sim 100 \%)$ was mostly achieved in the lowest concentration level (Hasnain et al., 2008). However, none of the studies conducted on the usage of oil palm biomass as adsorbent tested its feasibility for the adsorption of nitrogen and phosphorus based nutrients. Hence, the subsequent sections of this paper focus on reviewing methods for the aforementioned purpose.

\section{GREEN EXTRACTION OF CELLULOSE FROM OIL PALM BIOMASS}

The extraction of cellulose from oil palm biomass has been well established over the years. Cellulose may come in many forms such as alpha-cellulose, microcrystalline cellulose, and nanocrystalline cellulose. Alpha-cellulose is the main focus in this paper as it is quicker to extract from oil palm biomass as compared to the extraction of microcrystalline and nanocrystalline cellulose and separate from adsorbate solution once it is used as an adsorbent. The green method has recently been the highlight amongst researchers due to its environmentally friendly advantages such as the usage of environmentally friendly chemicals (i.e. formic acid and acetic acid) (Nazir et al., 2013). This could eliminate the use of sodium chlorite as a bleaching agent due to its ability to release chlorine ions during the extraction of cellulose from oil palm biomass.

The green method can further be categorised into eco-friendly reagent, ionic liquid, ozonolysis, and hydrothermal pre-treatment (Noorshamsiana et al., 2017). However, ozonolysis and hydrothermal pretreatment methods are not suitable for the extraction of cellulose from palm oil biomass. This is because ozonolysis generally only removes the high content of lignin neglecting the removal of hemicellulose from the lignocellulosic composition (Noorshamsiana et al., 2017). Meanwhile, hydrothermal pretreatment is mainly used in the extraction of glucose for bio-sugar production and bioethanol production (Malaysia Innovation Agency, 2013). In lieu, only eco-friendly reagent and ionic liquid shall be discussed in this section. 


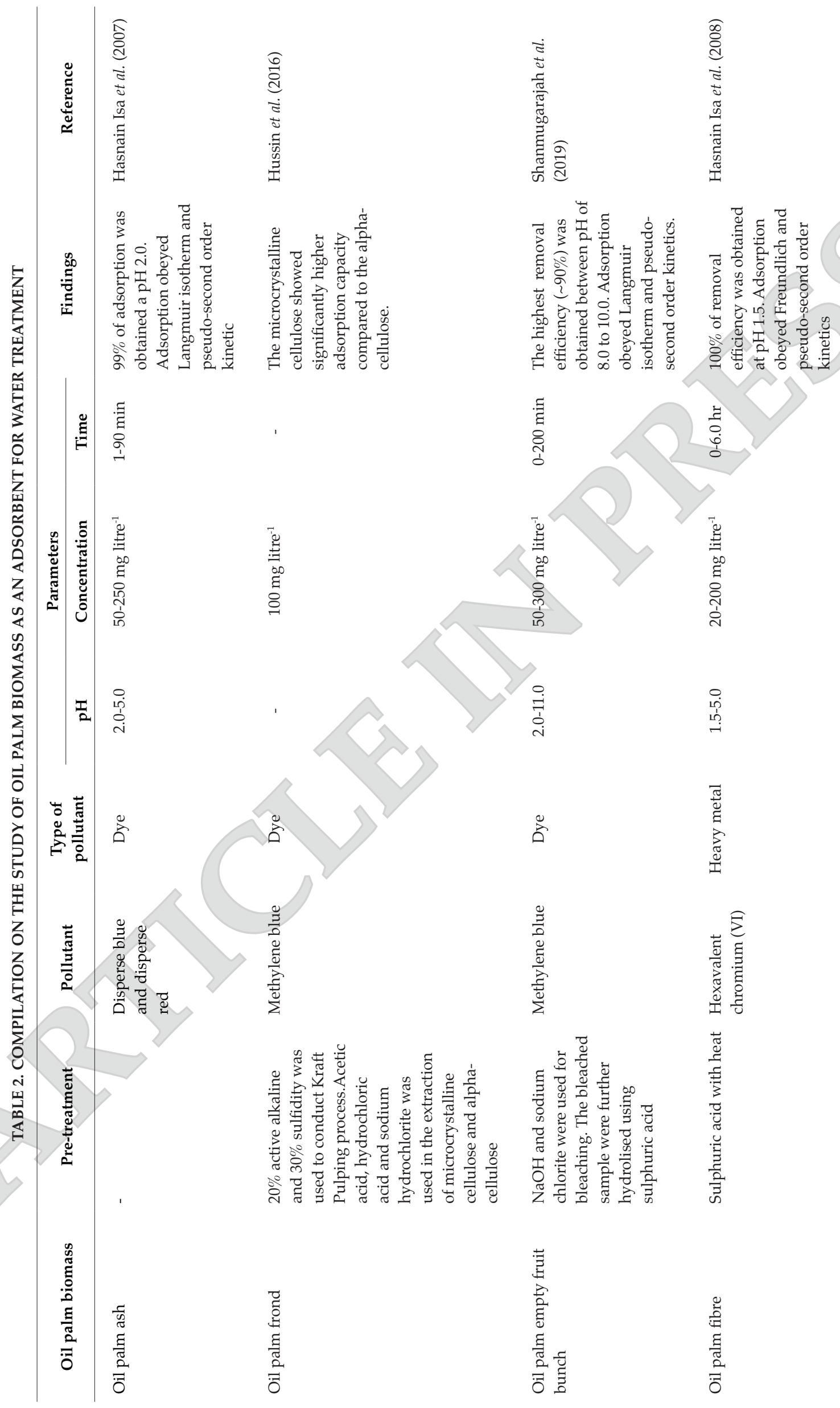




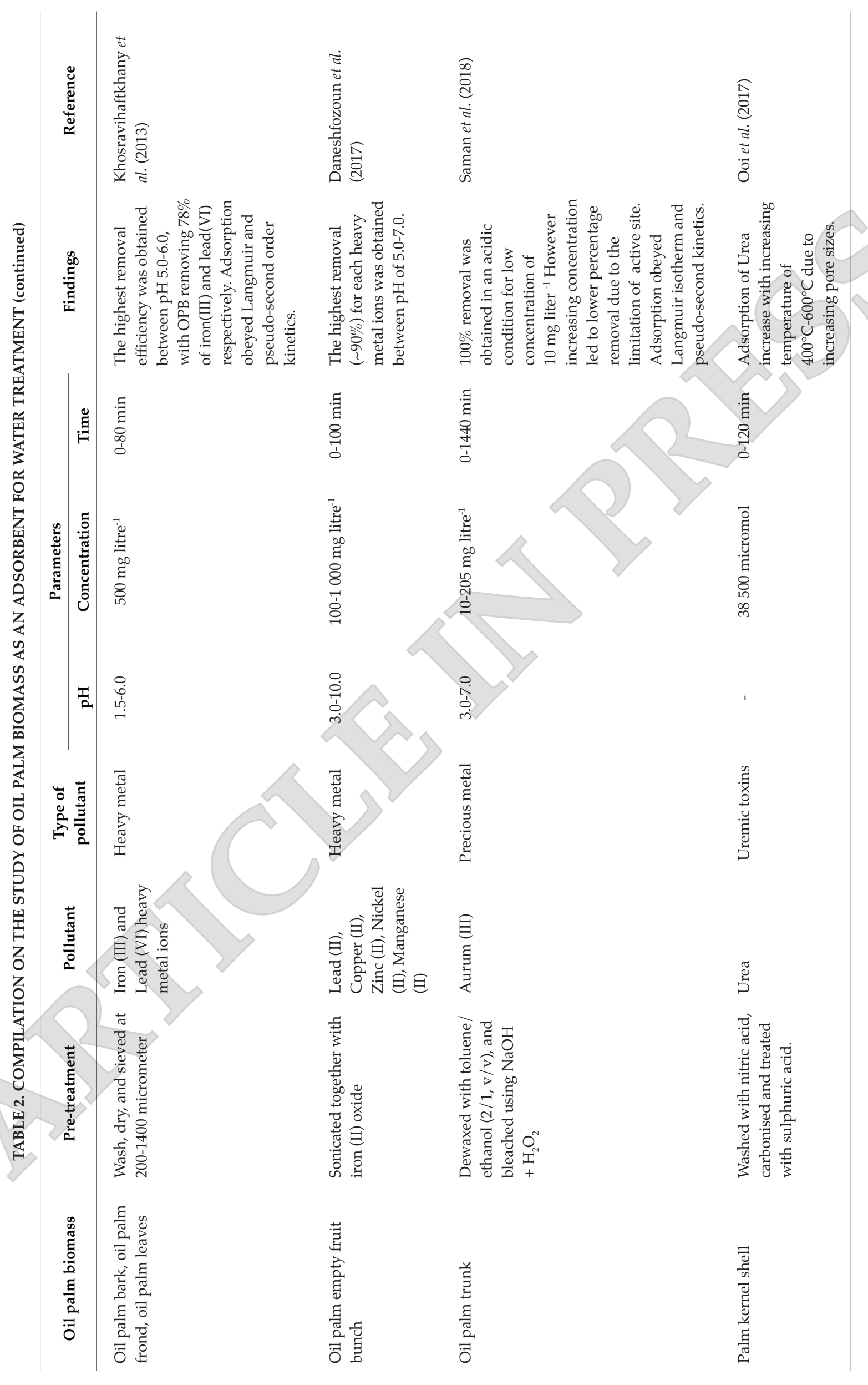




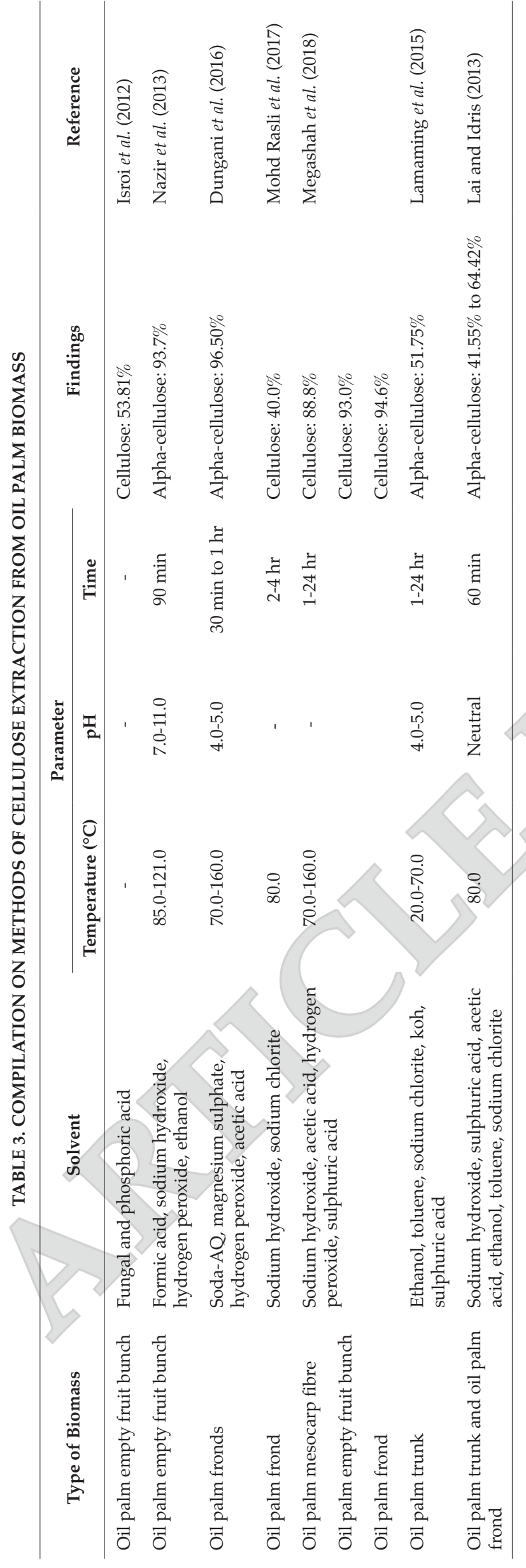

Table 3 summarises the methods of cellulose extraction from oil palm biomass. Thus far, cellulose extraction from oil palm biomass could be achieved at a minimum yield of $40 \%$ using conventional solvents as a bleaching agent. According to Nazir et al. (2013), the replacement of sodium chlorite as a bleaching agent by a mixture solution of formic acid with hydrogen peroxide gives a great advantage in reducing the amount of hazardous ions (chloride ions) released. Coupled with steam explosion, this method can soften the lignin and gives better penetration of the bleaching agent to remove lignin and hemicellulose easily. An estimation of $93.7 \%$ of alpha-cellulose with $70 \%$ crystallinity was obtained using the method. This proves the efficiency of formic acid with hydrogen peroxide when it is coupled with steam explosion method.

Ionic liquid is another effective method in removing lignin and hemicellulose from the lignocellulosic material that originated from oil palm biomass (Noorshamsiana et al., 2017). Ionic liquid is also known as a designers' solvent due to its strong dissolution properties which are made suitable to breakdown complex macromolecules and polymeric materials in the recalcitrant cellulose (Tan and Lee, 2012). According to Mohtar et al. (2017), ionic liquid's superior solvency properties came from its capability to disrupt strong linkages between cellulose and lignin via hydrogen bond and dipole bond formation. An added advantage of ionic liquid's method of extraction is the ability to recycle the solvent used for extraction purposes, this method also provides an alternative to replace the usage of harmful organic solvents (Mohtar et al., 2017). However, the solvent used to perform ionic liquid's method is indeed costly. It is also of high viscosity and is usually less effective in removing hemicellulose compared to acid hydrolysis (Jana and Ulla, 2011). Hence, there was a need for further alkaline treatment in the process to improve the yield of cellulose (Mohtar et al., 2017).

\section{MODIFICATION OF CELLULOSE}

After most of the alpha-cellulose is extracted, it can be modified chemically to enhance the electrostatic attraction between the adsorbent and adsorbate. Since nitrate and phosphate are negatively charged naturally, it would be of advantage if the adsorbent is positively charged. A modification method proposed by Orlando et al. (2002) using epichlorohydrin, dimethylformamide, pyridine, and dimethylamine has inspired many researchers to continue the method of modification and altered to suit different conditions. This method was tested and repeated on a few other lignocellulosic materials such as Moringa oleifera hull, lauan sawdust, coconut husk, rice hull, persimmon tealeaf, pine bark 
sugarcane bagasse (Orlando et al., 2002), banana stem (Anirudhan et al., 2006), wheat straw (Wang et al., 2007), and corn stalk (Fan and Zhang, 2018). The findings obtained from the studies showed encouraging results with the adsorption of $80 \%-50 \%$ for nitrate and up to $90 \%$ for phosphate depending on the individual or selective adsorption (Orlando et al., 2002; Anirudhan et al., 2006; Wang et al., 2007; Fan and Zhang, 2018). However, in those studies, there was no proper pre-treatment done to extract the cellulose from the lignocellulosic material. This might eventually affect the attachment of the cations towards the lignocellulosic material. Neither were most of the papers studying the selectivity of nitrate and phosphate nutrient adsorption. In lieu, it was more towards the individual adsorption of nitrate or phosphate nutrient onto the functionalised cellulose of lignocellulosic material.

Aside from the typical cationisation, there were a few studies on creating a neutral charge modification towards commercial cellulose (Anirudhan and Senan, 2011; Anirudhan et al., 2012). Anirudhan and Senan (2011) modified commercial cellulose by grafting it with iron(III) and amino-functionalised poly(glycidylmethacrylate). The modified commercial cellulose showed good adsorption towards phosphate at a $\mathrm{pH}$ of 6.0, with a constant agitation of $200 \mathrm{rpm}$ for $2.0 \mathrm{hr}$ of contact time under room temperature of $20^{\circ} \mathrm{C}$. These parameters assisted in the adsorption of phosphate, achieving the removal of $99.1 \%$. Although the parameters and result outcome were promising, the modification was conducted onto commercial cellulose and would impose a higher costing price as compared to sourcing it from biomass. Another study conducted by Anirudhan et al. (2012) grafted commercial cellulose with epichlorohydrin, and polyethyleneimine with $\mathrm{N}, \mathrm{N}^{\prime}$-methylene bisacrylamide as a crosslinking agent and azetobis isobutyro nitrile as initiator. This method also showed favourable phosphate adsorption with the removal of $99.6 \%$ at $\mathrm{pH} 4.5$ for $180 \mathrm{~min}$ of contact time. As the desired $\mathrm{pH}$ is lower, it is worth noting that the phosphate ions which were predominant in the study were $\mathrm{H}_{2} \mathrm{PO}_{4}^{-}$instead of the typical $\mathrm{PO}_{4}^{3-}$. This is due to the point of zero charge $\mathrm{pH}$ of the functionalised cellulose which is $\mathrm{pH} 4.8$. Hence, any $\mathrm{pH}$ more than $\mathrm{pH} 4.8$ will cause the surface of the adsorbent to have a negative charge instead of a positive (Anirudhan et al., 2012). They were causing the cationic ends attached to the adsorbent to repel the adsorbate.

\section{CHALLENGES AND FUTURE DIRECTION}

The main challenge in the study of adsorption of nitrate and phosphate anion nutrients is the tendency of adsorbent to perform selective adsorption towards both desired nutrients. Thus far, many studies had been conducted to adsorb nitrate and phosphate anion nutrients with a variety of adsorbent material. However, most studies are conducted with either anion nutrient present in the sample solution instead of having both the existences of anion nutrient simultaneously in the sample solution (Keränen et al., 2013; Qiao et al., 2019; Stjepanović et al., 2019). These studies would only provide an ideal situation instead of a real-life application due to other co-existing anion nutrients present which might lower the adsorption capacity of nitrate and phosphate anion nutrients in real-life application.

As for the number of researchers who had studied on the selectivity of anion nutrients in the effluent, the outcome showed that the selectivity adsorption is fayourable towards sulphate anion (Orlando et al., 2002; Sehaqui et al., 2016). Meanwhile, in the presence of only nitrate and phosphate anion nutrients in the effluent the outcome contradicts amongst the researchers as in some situation, the nitrate anion is much favourable due to single negative electron needed to be filled (Orlando et al., 2002). Others found that with the requirement of three negative electrons, phosphate anion, it is stronger to attract the cationic ends of the adsorbent (Sehaqui et al., 2016). Therefore, the need of creating an adsorbent which is able to balance the selectivity of adsorption towards nitrate and phosphate anion nutrients in the presence of other anion nutrients would be another challenge in the field.

Another challenging part of this area of study is to functionalise the extracted cellulose to obtain the positively charged ends that fulfil the criteria of green chemistry. This positively charged end enables the cellulose to act as an adsorbent in adsorbing the nitrate and phosphate, which is negatively charged, via electrostatic attraction. Although there are numerous methods introduced to functionalise the extracted cellulose, these functionalisation methods kept focusing on only targeting the hydroxyl group on $6^{\text {th }}$ carbon (C6). Since C6 hydroxyl group is the primary group, it is easier to functionalise it as it is more reactive (Börjesson and Westman, 2015). However, if the functionalisation method can focus even on C2 and C3 hydroxyl groups, it would increase the number of active sites in the adsorbent for nitrate and phosphate anion nutrients.

As for the parameters of adsorption, the $\mathrm{pH}$ of effluent is expected to remain in the neutral range, at ambient temperature and the concentration is of the pollutant could vary significantly. Therefore, to enable the application of the modified adsorbent directly by the aquaculture industry, the adsorbent should be robust and able to perform effectively without $\mathrm{pH}$ adjustor, water heater/cooler and concentration level indicator. 


\section{CONCLUSION}

Oil palm biomass is an excellent representation of lignocellulosic material in Malaysia due to its abundant amount produced every year. Therefore, it would be a significant step forward in using the oil palm biomass as an added feature of nitrate and phosphate anion nutrients adsorbent in order to expand its product value. With proper practice of extraction and modification of cellulose using green chemicals into effective adsorbent, it can contribute towards the safety of receiving water bodies from excessive nitrate and phosphate nutrients.

\section{ACKNOWLEDGEMENT}

The authors are grateful for the financial support given from Long Term Research Grant Scheme (LRGS) 1/2018 (UTAR-4411/S01) (UTM PY/2020/ 03532), Ministry of Higher Education.

\section{REFERENCES}

Abdullah, N and Gerhauser, H (2008). Bio-oil derived from empty fruit bunches. Fuel, 87(12): 2606-2613.

Abdullah, N and Sulaiman, F (2013). The oil palm wastes in Malaysia. Biomass Now - Sustainable Growth and Use (Matovic, M D ed.). IntechOpen.

Abnisa, F; Daud, W M A W; Husin, W N W and Sahu, J N (2011). Utilization possibilities of palm shell as a source of biomass energy in Malaysia by producing bio-oil in pyrolysis process. Biomass and Bioenergy, 35(5): 1863-1872.

Abnisa, F; Arami-Niya, A; Wan Daud, W M A; Sahu, J N and Noor, I M (2013). Utilization of oil palm tree residues to produce bio-oil and bio-char via pyrolysis. Energy Conversion and Management, 76: 1073-1082.

Akinbile, CO and Yusoff, MS (2012). Assessing water hyacinth (Eichhornia crassopes) and lettuce (Pistia stratiotes) effectiveness in aquaculture wastewater treatment. Int. J. Phytoremediation, 14(3): 201-211.

Anirudhan, T S; Noeline, B F and Manohar, D M (2006). Phosphate removal from wastewaters using a weak anion exchanger prepared from a lignocellulosic residue. Environmental Science and Technology, 40(8): 2740-2745.

Anirudhan, T S; Rauf, T A and Rejeena, S R (2012). Removal and recovery of phosphate ions from aqueous solutions by amine functionalized epichlorohydrin-grafted cellulose. Desalination, 285: 277-284.
Anirudhan, T S and Senan, P (2011). Adsorption of phosphate ions from water using a novel cellulosebased adsorbent. Chemistry and Ecology, 27(2): 147164.

Awalludin, M F; Sulaiman, O; Hashim, R and Nadhari, W N A W (2015). An overview of the oil palm industry in Malaysia and its waste utilization through thermochemical conversion, specifically via liquefaction. Renewable and Sustainable Energy Reviews, 50: 1469-1484.

Börjesson, M and Westman, G (2015). Crystalline Nanocellulose - Preparation, Modification, and Properties. Cellulose - Fundamental Aspects and Current Trends, p. 159-191.

Castine, S A; McKinnon, A D; Paul, N A; Trott, L $A$ and de Nys, R (2013). Wastewater treatment for land-based Aquaculture: Improvements and valueadding alternatives in model systems from Australia. Aquaculture Environment Interactions, 4(3): 285-300.

Cripps, S J and Bergheim, A (2000). Solids management and removal for intensive land-based aquaculture production systems. Aquacultural Engineering, 22(1-2): 33-56.

Daneshfozoun, S; Abdullah, M A and Abdullah, B (2017). Preparation and characterization of magnetic biosorbent based on oil palm empty fruit bunch fibers, cellulose and Ceiba pentandra for heavy metal ions removal. Industrial Crops and Products, 105: 93103.

Dungani, R; Owolabi, AF; Saurabh, CK; Abdul Khalil, H P S; Tahir, P M; Hawzan, C I C M; Ajijolakewu, K A; Masri, M M; Rosamah, E and Aditiawati, P (2017). Preparation and fundamental characterization of cellulose nanocrystal from oil palm fronds biomass. J. Polymers and the Environment, 25(3): 692-700.

Fan, C and Zhang, Y (2018). Adsorption isotherms, kinetics and thermodynamics of nitrate and phosphate in binary systems on a novel adsorbent derived from corn stalks. J. Geochemical Exploration, 188: 95-100.

FAO (2016). Fisheries and Aquaculture - National Aquaculture Sector Overview - Malaysia. Food and Agriculture Organization of the United Nation. http: / / www.fao.org/ fishery / countrysector / naso malaysia/en, accessed on 19 April 2020.

Hamoudi, S and Belkacemi, K (2013). Adsorption of nitrate and phosphate ions from aqueous solutions using organically-functionalized silica materials: Kinetic modelling. Fuel: The Science and Technology of Fuel and Energy, 110: 107-113. 
Hasnain, I M; Ibrahim, N; Aziz, H A; Adlan, M N; Sabiani, N H M; Zinatizadeh, A A L and Kutty, S R M (2008). Removal of chromium (VI) from aqueous solution using treated oil palm fibre. J. Hazardous Materials, 152(2): 662-668.

Hasnain, I M; Siew L L; Asaari, F A H; Aziz, H A; Azam, R N and Dhas, J P A (2007). Low cost removal of disperse dyes from aqueous solution using palm ash. Dyes and Pigments, 74(2): 446-453.

Hokkanen, S; Bhatnagar, A and Sillanpää, M (2016). A review on modification methods to cellulosebased adsorbents to improve adsorption capacity. Water Research, 91: 156-173.

Hussin, M H; Pohan, N A; Garba, Z N; Kassim, M J; Rahim, A A; Brosse, N; Yemloul, M; Fazita, M R N and Haafiz, M K M (2016). Physicochemical of microcrystalline cellulose from oil palm fronds as potential methylene blue adsorbents. Int. J. Biological Macromolecules, 92: 11-19.

Isroi; Ishola, $\mathrm{M}$ M; Millati, R; Syamsiah, S; Cahyanto, M N; Niklasson, $\mathrm{C}$ and Taherzadeh, $\mathrm{M}$ J (2012). Structural changes of oil palm empty fruit bunch (OPEFB) after fungal and phosphoric acid pretreatment. Molecules, 17(12): 14995-15012.

Jana, H and Ulla, L (2011) Ionic Liquids in the Performance of Lignocellulosic Biomass, in Ionic Liquids: Applications and Perspectives. Intech. p. 545-560.

Kamil, N N and Omar, S F (2016). Climate Variability and its Impact on the Palm Oil Industry. Oil Palm Industry Economics J., 16: 18-30.

Karthikeyan, P; Banu, H A T and Meenakshi, S (2019). Removal of phosphate and nitrate ions from aqueous solution using La 3+ incorporated chitosan biopolymeric matrix membrane. Int. J. Biological Macromolecules, 124: 492-504.

Keränen, A; Leiviskä, T; Gao, B Y; Hormi, O and Tanskanen, J (2013). Preparation of novel anion exchangers from pine sawdust and bark, spruce bark, birch bark and peat for the removal of nitrate. Chemical Engineering Science, 98: 59-68.

Khosravihaftkhany, S; Morad, N; Teng, T T; Abdullah, AZ and Norli, I (2013). Biosorption of Pb(II) and Fe(III) from aqueous solutions using oil palm biomasses as adsorbents. Water, Air and Soil Pollution., 224(3): 1-14.

Kim, J; Hwang, M J; Lee, S J; Noh, W; Kwon, J M; Choi, J S and Kang, C M (2016). Efficient recovery of nitrate and phosphate from wastewater by an amine-grafted adsorbent for cyanobacterial biomass production. Bioresource Technology, 205: 269-273.
Kioussis, D R; Wheaton, F W and Kofinas, P (2000). Reactive nitrogen and phosphorus removal from aquaculture wastewater effluents using polymer hydrogels. Aquacultural Engineering, 23(4): 315332.

Klemm, D; Heublein, B; Fink, H P and Bohn, A (2005). Cellulose: Fascinating biopolymer and sustainable raw material. Angewandte Chemie International Edition, 44(22): 3358-3393.

Kumneadklang, S; O-Thong, S and Larpkiattaworn, S (2019). Characterization of cellulose fiber isolated from oil palm frond biomass. Materials Today: Proceedings, 17: 1995-2001.

Kushairi, A; Ong-Abdullah, M; Nambiappan, B; Hishamuddin, E; Bidin, M N I Z; Ghazali, R; Subramaniam, V; Sundram, S and Parveez, G K A (2019). Oil palm economic performance in Malaysia and R\&D Progress in 2018. J. Oil Palm Res. Vol. 31(2): 165-194.

Lamaming, J; Hashim, R; Sulaiman, O; Leh, C P; Sugimoto, T and Nordin, N A (2015). Cellulose nanocrystals isolated from oil palm trunk. Carbohydrate Polymers. Elsevier Ltd., 127: 202-208.

Lamaming, J; Chew, S C; Hashim, R; Sulaiman, O and Sugimoto, T (2017). Extraction of Microcrystalline Cellulose from Oil Palm Trunk. Technical Report, 96(11): 513-518.

Lee, S Y; Choi, J-W; Song, K G; Choi, K; Lee, Y J and Jung, K-W (2019). Adsorption and mechanistic study for phosphate removal by rice husk-derived biochar functionalized with $\mathrm{Mg} / \mathrm{Al}$-calcined layered double hydroxides via co-pyrolysis. Composites Part B: Engineering, 176: 107209.

Lefatshe, K; Muiva, C M and Kebaabetswe, L P (2017). Extraction of nanocellulose and in-situ casting of $\mathrm{ZnO} /$ cellulose nanocomposite with enhanced photocatalytic and antibacterial activity. Carbohydrate Polymers, 164: 301-308.

Lin, Y; Jing, S; Lee, D and Wang, T (2002). Nutrient removal from aquaculture wastewater using a constructed wetlands system. Aquaculture, 209: 169-184.

Lai, L W and Idris, A (2013). Disruption of oil palm trunks and fronds by microwave-alkali pretreatment. BioResources, 8(2): 2792-2804.

Malaysian-German Chamber of Commerce and Industry (2017). Oil Palm Biomass \& Biogas In Malaysia. EU-Malaysia Chamber of 
Commerce and Industry (EUMCCI), 15. https:// businessmalaysia.eu/admin / js / fileman / Uploads / BiomassBiogas2018_Final_20180508.pdf, accessed on 20 April 2020.

Malaysia Innovation Agency (2013). National Biomass Strategy 2020: New wealth creation for Malaysia's palm oil industry. https://www. cmtevents.com/MediaLibrary/ BStgy2013RptAIM. pdf, accessed on 3 January 2019.

Megashah, L N; Ariffin, H; Zakaria, M R and Hassan, M A (2018). Properties of Cellulose Extract from Different Types of Oil Palm Biomass. IOP Conference Series: Materials Science and Engineering, 368(1): 1-11.

Mohamed Omar, A F (2017a). Fisheries Country Profile: Malaysia. http://www.seafdec.org/ fisheries-country-profile-malaysia/, accessed on 3 January 2019.

Mohamed Omar, A F (2017b). Fisheries Country Profile: Malaysia - SEAFDEC. http://www. seafdec.org/fisheries-country-profile-malaysia/, accessed on 3 January 2019.

Mohd, R S R A; Ahmad, I; Mat, L A and Hamzah, A (2017). Extraction and Characterization of Cellulose from Agricultural Residue - Oil Palm Fronds. Malaysian J. Analytical Science, 21(5): 1065-1073.

Mohtar, S S; Tengku, M B T N Z; Md Noor, A M; Shaari, N and Mat, H (2017). An ionic liquid treatment and fractionation of cellulose, hemicellulose and lignin from oil palm empty fruit bunch. Carbohydrate Polymers, 166: 291-299.

Nazir, M S; Wahjoedi, B A; Yussof, A W and Abdullah, M A (2013). Eco-Friendly Extraction and Characterization of Cellulose from Oil Palm Empty Fruit Bunches, BioResources, 8(2): 2161-2172.

$\mathrm{Ng}, \mathrm{L} \mathrm{Y}$; Ng, C Y; Ong, C B and Mohammad, A $W$ (2018). A review of the management of inflow water, wastewater and water reuse by membrane technology for a sustainable production in shrimp farming. J. Water Process Engineering, 23: 27-44.

Noorshamsiana, A W; Nur Eliyanti, A O; Fatiha, I and Astimar, A A (2017). A Review on Extraction Processes of Lignocellulosic Chemicals from Oil Palm Biomass. J. Oil Palm Res. Vol. 29(4): 512-527.

Onoja, E; Chandren, S; Abdul Razak, F I; Mahat, N A and Wahab, R A (2018). Oil Palm (Elaeis guineensis) Biomass in Malaysia: The Present and Future Prospects. Waste and Biomass Valorization., 10(8): 1-19.
Ooi, C H; Sim, Y L and Yeoh, F Y (2017). Urea adsorption by activated carbon prepared from palm kernel shell. AIP Conference Proceedings, 1865: 1-6.

Orlando, U S; Baes, A U; Nishijima, W and Okada, M (2002). Preparation of agricultural residue anion exchangers and its nitrate maximum adsorption capacity. Chemosphere, 48(10): 1041-1046.

Pan, J; Gao, B; Song, W; Xu, X; Jin, B and Yue, Q (2018). Column adsorption and regeneration study of magnetic biopolymer resin for perchlorate removal in presence of nitrate and phosphate. J. Cleaner Production, 213: 762-775.

Qiao, H; Mei, L; Chen, G; Liu, H; Peng, C; Ke, F; Hou, R; Wan, X and Cai, H (2019). Adsorption of nitrate and phosphate from aqueous solution using amine cross-linked tea wastes. Applied Surface Science, 483: 114-122.

Saman, N; Tan, J W; Mohtar, S S; Kong, H; Lye, J W P; Johari, K; Hassan, H and Mat, H (2018). Selective biosorption of aurum(III) from aqueous solution using oil palm trunk (OPT) biosorbents: Equilibrium, kinetic and mechanism analyses. Biochemical Engineering J., 136: 78-87.

Sehaqui, H; Mautner, A; Perez, U; Larraya, D; Pfenninger, N; Tingaut, $\mathrm{P}$ and Zimmermann, $\mathrm{T}$ (2016). Cationic cellulose nanofibers from waste pulp residues and their nitrate, fluoride, sulphate and phosphate adsorption properties. Carbohydrate Polymers, 135: 334-340.

Shanmugarajah, B; Chew, I M L; Mubarak, N M; Choong, T S Y; Yoo, C K and Tan, K W (2019). Valorization of palm oil agro-waste into cellulose biosorbents for highly effective textile effluent remediation. J. Cleaner Production, 210: 697709.

Shojaipour, M; Ghaemy, $M$ and Amininasab, S M (2020). Removal of NO3- ions from water using bioadsorbent based on gum tragacanth carbohydrate biopolymer. Carbohydrate Polymers, 227(3): 115367.

Shuit, S H; Tan, K T; Lee, K T and Kamaruddin, A $H$ (2009). Oil palm biomass as a sustainable energy source: A Malaysian case study. Energy, 34(9): 12251235.

Stjepanović, M; Velić, N; Lončarić, A; Gašo-Sokač, D; Bušić, V and Habuda-Stanić, M (2019). Adsorptive removal of nitrate from wastewater using modified lignocellulosic waste material. J. Molecular Liquids, 285: 535-544. 
Sumathi, S; Chai, S P and Mohamed, A R (2008). Utilization of oil palm as a source of renewable energy in Malaysia. Renewable and Sustainable Energy Reviews, 12(9): 2404-2421.

Tan, H T and Lee, K T (2012). Understanding the impact of ionic liquid pretreatment on biomass and enzymatic hydrolysis. Chemical Engineering J., 183: 448-458.

Turcios, A E and Papenbrock, J (2014). Sustainable Treatment of Aquaculture Effluents - What Can We Learn from the Pst for the Future? Sustainability, 6: 836-856.

Umar, M S; Jennings, $\mathrm{P}$ and Urmee, $\mathrm{T}$ (2013). Strengthening the palm oil biomass Renewable Energy industry in Malaysia. Renewable Energy, 60: 107-115.

Wang, W Y; Yue, Q Y; Xu, X; Gao, B Y; Zhang, J; $\mathrm{Li}, \mathrm{Q}$ and $\mathrm{Xu}, \mathrm{J}$ T (2010). Optimized conditions in preparation of giant reed quaternary amino anion exchanger for phosphate removal. Chemical Engineering J., 157(1): 161-167.

Wang, Y; Gao, B Y; Yue, W W and Yue, Q Y (2007). Preparation and utilization of wheat straw anionic sorbent for the removal of nitrate from aqueous solution. J. Environmental Sciences, 19(11): 1305-1310.
Wu, K; Li, Y; Liu, T; Huang, Q; Yang, S; Wang, W and Jin, $P$ (2019). The simultaneous adsorption of nitrate and phosphate by an organic-modified aluminummanganese bimetal oxide: Adsorption properties and mechanisms. Applied Surface Science, 478(13): 539-551.

Yin, Q; Zhang, B; Wang, R and Zhao, Z (2017). Biochar as an adsorbent for inorganic nitrogen and phosphorus removal from water: A review. Environmental Science and Pollution Research, 24(34): 26297-26309.

Yin, Q; Ren, H; Wang, R and Zhao, Z (2018). Evaluation of nitrate and phosphate adsorption on Al-modified biochar: Influence of $\mathrm{Al}$ content. Science of the Total Environment, 631-632: 895903.

Yu, L J; Rengasamy, K; Lim, KY; Tan, L S; Tarawneh, M; Zulkoffli, Z B and Se, Y E N (2019). Comparison of activated carbon and zeolites' filtering efficiency in freshwater. J. Environmental Chemical Engineering, 7(4): 103223.

Zakaria, M R; Hirata, S and Hassan, M A (2014). Combined pretreatment using alkaline hydrothermal and ball milling to enhance enzymatic hydrolysis of oil palm mesocarp fiber. Bioresource Technology, 169: 236-243. 